\title{
Weight gain and menstrual abnormalities between users of Depo-provera and Noristerat
}

\author{
Yusuf Abisowo Oshodi*, Joy Oyinyechi Agbara, Olamide O. Ade-fashola, \\ Fatimat Motunrayo Akinlusi, Haleemah Folashade Olalere, Taiwo O. Kuye
}

Department of Obstetrics and Gynecology, Lagos State University Teaching Hospital, Ikeja, Lagos, Nigeria

Received: 28 April 2019

Accepted: 14 May 2019

\section{*Correspondence:}

Dr. Yusuf Abisowo Oshodi,

E-mail: yusufoshodi@gmail.com

Copyright: () the author(s), publisher and licensee Medip Academy. This is an open-access article distributed under the terms of the Creative Commons Attribution Non-Commercial License, which permits unrestricted non-commercial use, distribution, and reproduction in any medium, provided the original work is properly cited.

\begin{abstract}
Background: Progesterone only injectable contraceptive provides long acting contraception against unwanted pregnancy. Alterations in menstrual pattern are a well known side effect of this effective contraceptive method. Objective of this study was to compare the weight gain and pattern of menstrual abnormalities in users of Depot Medroxyprogesterone Acetate (DMPA) and Norethisterone Enanthate (Noristerat) in LASUTH.

Methods: Retrospective comparative study conducted over a 3year period (January 2013 to December 2015) and involving 237 subjects who used injectable hormonal contraceptive (either DMPA or Noristerat). Case records of all the subjects were retrieved and information obtained on socio-demographic data, parity, previous contraceptive method and reason for discontinuation within one year of usage. Other information including subjects' weight, menstrual cycle length and pattern, and side effects were collected at 3,6 and 12 months for DMPA group and 2, 4 and 12 months interval for Noristerat group. Data obtained were analyzed using statistical packages for social sciences (version 19).

Results: The combined mean age was $34.15 \pm 1.36$ years. The mean weight at commencement was $68.16 \mathrm{~kg}$ for DMPA and $66.61 \mathrm{~kg}$ for Noristerat users while after a year, it significantly increased to $71.27 \mathrm{~kg}$ for DMPA and $69.07 \mathrm{~kg}$ for Noristerat users $(\mathrm{P}<0.05)$. No change in menstrual pattern was noted in $10 \%$ of DMPA and $7 \%$ of Noristerat users while $60 \%$ of DMPA and $57 \%$ of Noristerat had amenorrhoea by the end one year period. Five percent each of DMPA and Noristerat users perceived weight gain as problem significant enough to discontinue both methods respectively. Overall, 24\% of DMPA and $19.1 \%$ of Noristerat users discontinued use after one year.

Conclusions: There were significant weight gain between users of DMPA and Noristerat which was not considered a problem. Amenorrhoea was the commonest menstrual abnormality responsible for discontinuation of either method.
\end{abstract}

Keywords: Depo-provera, Menstrual abnormalities, Noristerat, Weight gain

\section{INTRODUCTION}

Unintended pregnancies pose significant Public Health risks. One consequence of unwanted pregnancy is induced abortion. ${ }^{1}$ And, because abortion though legal in Nigeria but the law restrictive, many of such procedures are conducted under unsafe conditions and this carries a substantial risk of maternal morbidity and mortality. It is estimated that about $25 \%$ of women who had induced abortion in Nigeria experience serious complications. ${ }^{1}$

After the birth of the first child, $80 \%$ of educated couples used spacing methods, whereas even after the birth of the third child, more than $50 \%$ of uneducated women did not. ${ }^{2}$ Hence education plays a key role in contraceptive 
acceptance and its use. Religious beliefs and cultural practices such as the desire for a male child are some of the factors responsible for poor use or non-usage of contraceptives in developing countries. ${ }^{3}$

Failure to utilize modern contraceptives leads to over population and increased demand on limited resources leading to wide scale poverty and deprivation. ${ }^{3}$ With the low ranking of most African countries on the human development index, there is no doubt that the smaller the family size, the better the upbringing and development of children. ${ }^{7}$ Among the various contraceptive methods available, hormonal agents are the most popular and most effective non-surgical method of contraception worldwide. ${ }^{4}$ The most popular of these methods are the combined oral contraceptive pills, although in Nigeria and Africa as a whole, the injectable hormonal contraceptives are gaining acceptance among clients seeking longer contraception. ${ }^{4}$ The injectable progesterone only contraceptive offer the advantage of not requiring storage and enabling women to maintain secrecy about their use of contraception, because members of their families may oppose the concept of birth control. ${ }^{5}$

Both progestogens are extremely effective in preventing pregnancy with a pregnancy rate close to zero. ${ }^{9}$ Injectable contraceptives are associated with multiple side effects with secondary amenorrhea being the most common menstrual abnormality; others include polymenorrhea and weight gain. ${ }^{5}$ However, the USFDA has discouraged their use for more than two consecutive years as evidence shows that prolonged use reduces bone mineral density; however, this loss generally seems to be temporary and reversible. $^{6}$

In view of the foregoing, this study seeks to compare the pattern of menstrual abnormalities and weight gain in users of DMPA and Noristerat among the users in our tertiary institution.

\section{METHODS}

This was a retrospective study carried out in the Family Planning Clinic of Lagos State University Teaching Hospital (LASUTH), Ikeja, Lagos over a 3-year period (January 2013 to December 2015) following approval from our institution's Health Research and Ethics Committee. Two hundred and thirty-seven subjects were involved in the study comprising 135 in the DMPA group and 102 in the Noristerat. Case records of all the subjects were retrieved and information was obtained within one year of usage.

Information obtained includes socio-demographic data (Age, marital status, occupation, educational levels and religion) and parity, previous contraceptive methods and reasons for discontinuation. Data on subject's weights, menstrual cycle length and patterns of irregularity were also retrieved from the records as documented during the first 2 months, the next 4 months following, up to 1 year of regular usage for Noristerat group and for the first 3 months, the following 6months and also up to 1 year of regular usage for the DMPA group.

\section{Statistical analysis}

The data obtained were analysed using SPSS version 20 (Chicago Illinois). Variables were represented using mean, standard deviation and cross tabulations were also performed. Comparative analysis of weight gain and menstrual abnormalities was done using student's paired $\mathrm{t}$-tests and independent $\mathrm{t}$ test. $\mathrm{P}$ value $<0.05$ was considered statistically significant. Level of confidence interval was set at $95 \%$.

\section{RESULTS}

One thousand, one hundred clients used the modern contraceptive methods within the 3-year study period. Intra-uterine contraceptive device was the commonest method used by 668 clients accounting for $60.72 \%$. Three hundred and ninety four subjects accounting for $35.82 \%$ used hormonal contraceptives. This comprises 237 $(21.55 \%)$ injectables (DMPA and Noristerat), 92 (8.36\%) for combined oral contraceptive pills, 43 (3.91\%) for progesterone only pills and $36(3.27 \%)$ for Implanon users. Twenty two $(2 \%)$ subjects used male condom and only $2(0.18 \%)$ subjects had tubal sterilization (Table 1$)$. The socio-demographic data revealed mean and age range of $34.15 \pm 1.36(20-47)$ years. Sixty five percent of the subject had tertiary education compared to $21 \%$ that had secondary, $11 \%$ primary and $5.5 \%$ without any formal education.

Table 1: Contraceptive uptake and types.

\begin{tabular}{|lll|}
\hline Contraceptive method used & Number of patients & Percentage of use \\
\hline IUCD & 668 & $60.72 \%$ \\
\hline Injectables (progesterone only) & 237 & $21.55 \%$ \\
\hline Combined oral contraceptives & 92 & $8.36 \%$ \\
\hline Progesterone only pills & 43 & $3.91 \%$ \\
\hline Implanon & 36 & $3.27 \%$ \\
\hline Condom & 22 & $2 \%$ \\
\hline Tubal sterilisation & 2 & $0.18 \%$ \\
\hline
\end{tabular}


There was statistically significant difference in the two group considering the educational level $(\mathrm{P}=0.04)$. Majority of the clients were Christian (76\%) while 19\% were Muslim. Majority of respondents were Para 3-4 in both groups but comparative analysis did not reveal any significant difference in both groups $(\mathrm{P}=0.71)$ (Table 2).
Table 3 shows average weight gain from commencement up till the end of the one year. In the Noristerat group, mean weight at the first visit was $66.61 \mathrm{~kg}$ (which was the starting weight) but this increased to $67.2 \mathrm{~kg}$ at 2 months, $68.03 \mathrm{~kg}$ at 4 months, and $69.07 \mathrm{~kg}$ at 12 months. The difference in mean weight at the end of 12 months was statistically significant $(\mathrm{p}$ value $=0.00)$.

Table 2: Socio-demographic distribution.

\begin{tabular}{|c|c|c|c|}
\hline Characteristics & Noristerat Freq (\%) & Depoprovera Freq (\%) & Differences Absolute $\mathbf{P}$ values \\
\hline \multicolumn{4}{|l|}{ Age (in years) } \\
\hline $20-24$ & $7(6.9)$ & $12(8.9)$ & \multirow{5}{*}{0.12} \\
\hline $25-29$ & $10(9.8)$ & $18(13.3)$ & \\
\hline $30-34$ & $38(37.3)$ & $42(31.1)$ & \\
\hline $35-39$ & $21(20.6)$ & $44(32.6)$ & \\
\hline \multirow[t]{2}{*}{$>40$} & $26(25.5)$ & $19(14.1)$ & \\
\hline & $102(43)$ & $135(57)$ & \\
\hline \multicolumn{4}{|l|}{ Religion } \\
\hline Christianity & $78(76.5)$ & $102(75.6)$ & \multirow{3}{*}{0.58} \\
\hline Islam & $21(20.6)$ & $25(18.5)$ & \\
\hline \multirow[t]{2}{*}{ Others } & $3(2.9)$ & $8(5.9)$ & \\
\hline & $102(43)$ & $135(57)$ & \\
\hline \multicolumn{4}{|l|}{ Educational level } \\
\hline None & $5(4.9)$ & $8(5.9)$ & \multirow{4}{*}{0.04} \\
\hline Primary & $4(3.9)$ & $22(16.3)$ & \\
\hline Secondary & $25(24.5)$ & $25(18.5)$ & \\
\hline \multirow[t]{2}{*}{ Tertiary } & 68 (66.7) & $80(59.3)$ & \\
\hline & $102(43)$ & 135 (57) & \\
\hline \multicolumn{4}{|l|}{ Parity } \\
\hline $1-2$ & $16(15.7)$ & $27(20.0)$ & \multirow{3}{*}{0.71} \\
\hline $3-4$ & $74(72.6)$ & $94(69.6)$ & \\
\hline \multirow[t]{2}{*}{$>=5$} & $12(11.8)$ & $14(10.4)$ & \\
\hline & $102(43)$ & $135(57)$ & \\
\hline
\end{tabular}

All the women in this study were married.

Table 3: Weight gain and injectable contraceptives.

\begin{tabular}{|llll|}
\hline & Weight $(\mathrm{kg})$ Mean & Mean difference & P value \\
\hline (A) Depo-provera & & & \\
\hline First visit & $68.16 \pm 9.84$ & 0 & 0.000 \\
\hline Second visit & $68.85 \pm 9.69$ & $0.9 \pm \pm 1.29$ & 0.000 \\
\hline Third visit & $69.75 \pm 9.90$ & $1.52 \pm 1.26$ & 0.000 \\
\hline A year & $71.27 \pm 10.09$ & & \\
\hline Noristerat & & 0 & 0.000 \\
\hline First visit & $66.61 \pm 9.02$ & $0.59 \pm 1.90$ & 0.000 \\
\hline Second visit & $67.2 \pm 8.69$ & $0.83 \pm 1.62$ & 0.000 \\
\hline Third visit & $68.03 \pm 8.42$ & $1.04 \pm 1.36$ & \\
\hline A year & $69.07 \pm 8.39$ & & 0.067 \\
\hline (B) Term & Type of IC & $71.27 \pm 10.09$ & \\
\hline A year & Noristerat & $69.07 \pm 8.39$ & \\
\hline & Depo-provera & & \\
\hline
\end{tabular}

In the DMPA group, mean weight at the first visit was $68.16 \mathrm{~kg}$ (which was the starting weight), and it increased to $68.85 \mathrm{~kg}, 69.75 \mathrm{~kg}$ and $71.27 \mathrm{~kg}$ at 3 months, 6 months and 12 months respectively. This observed difference in 
mean weight also reached statistical significance (P value $=0.00)$. However, comparing the mean weight gain between users of DMPA and Noristerat at the $1^{\text {st }}, 2^{\text {nd }}, 3^{\text {rd }}$, and after a year visit, using an independent t-test, there were no statistical significant difference between them as $\mathrm{P}$-value $=0.067$ at each of the visits.

Table 4 shows menstrual patterns in both categories of women from commencement to the end of 12 months. In the Noristerat group, $21.05 \%$ experienced no change in their menstrual cycles at 2 months, but this proportion dropped to $2.44 \%$ at 12 months. In the DMPA group
$7.75 \%$ of the patient experienced no change in their menstrual cycle at 3 months. This proportion however reduced to $0.87 \%$ at 12 months. Prolonged spotting and intermenstrual bleeding was common in both groups. Amenorrhea was the most common side-effect, accounting for $60 \%$ and $57.32 \%$ at the end of 12 months in the DMPA and Noristerat groups respectively. While there was statistically significant difference in both groups during the first follow-up visit, there was no statistically difference in the second and last visit one year later.

Table 4: Menstrual patterns experienced by users of injectable contraceptives.

\begin{tabular}{|c|c|c|c|c|c|}
\hline Menstrual pattern (first follow-up visit) & Noristerat & $\%$ & Depoprovera & $\%$ & P value \\
\hline No change & 20 & 21 & 10 & 8 & \multirow{4}{*}{0.01} \\
\hline Increased flow & 25 & 26 & 24 & 19 & \\
\hline Reduced flow & 35 & 37 & 55 & 43 & \\
\hline Amenorrhoea & 15 & 16 & 40 & 31 & \\
\hline Total & 95 & & 129 & & \\
\hline \multicolumn{6}{|l|}{ Menstrual pattern (second follow-up visit) } \\
\hline No change & 5 & 6 & 2 & 2 & \multirow{4}{*}{0.3} \\
\hline Increased flow & 13 & 14 & 11 & 9 & \\
\hline Reduced flow & 42 & 47 & 62 & 50 & \\
\hline Amenorrhoea & 30 & 33 & 48 & 39 & \\
\hline Total & 90 & & 123 & & \\
\hline \multicolumn{6}{|l|}{ Menstrual pattern (a year follow-up visit) } \\
\hline No change & 2 & 2 & 1 & 1 & \multirow{4}{*}{0.89} \\
\hline Increased flow & 8 & 10 & 9 & 8 & \\
\hline Reduced flow & 25 & 30 & 36 & 31 & \\
\hline Amenorrhoea & 47 & 57 & 69 & 60 & \\
\hline Total & 82 & & 115 & & \\
\hline
\end{tabular}

Table 5: Discontinuation rate.

\begin{tabular}{|lllll|}
\hline & Depoprovera & \multicolumn{3}{l|}{ Noristerat } \\
\cline { 2 - 5 } Discontinuation rates & Count & $\mathbf{\%}$ & Count & $\mathbf{\%}$ \\
\hline At first follow-up visit & 6 & $4 \%$ & 7 & $6.86 \%$ \\
\hline At second follow-up visit & 12 & $9 \%$ & 5 & $4.90 \%$ \\
\hline At 1 year & 20 & $15 \%$ & 8 & $7.84 \%$ \\
\hline Continued & 97 & $72 \%$ & 82 & $80.39 \%$ \\
\hline Total & $\mathbf{1 3 5}$ & $\mathbf{1 0 0 \%}$ & $\mathbf{1 0 2}$ & $\mathbf{1 0 0 \%}$ \\
\hline
\end{tabular}

Table 6: Reasons for discontinuation.

\begin{tabular}{|lllll|}
\hline \multirow{2}{*}{ Reasons for discontinuation } & Depoprovera & \multicolumn{3}{l|}{ Noristerat } \\
\cline { 2 - 5 } & Count & $\mathbf{\%}$ & Count & $\mathbf{\%}$ \\
\hline Amenorrhoea & 26 & $68 \%$ & 12 & $60 \%$ \\
\hline Prolonged spotting PV & 6 & $16 \%$ & 4 & $20 \%$ \\
\hline Irregular/ intermenstrual bleeding & 4 & $11 \%$ & 3 & $15 \%$ \\
\hline Weight gain & 2 & $5 \%$ & 1 & $5 \%$ \\
\hline Total & $\mathbf{3 8}$ & $\mathbf{1 0 0 \%}$ & $\mathbf{2 0}$ & $\mathbf{1 0 0 \%}$ \\
\hline
\end{tabular}


Thirty-eight subjects $(28 \%)$ in the DMPA group discontinued the method compared to 20 (19.61\%) Noristerat users after one year $(\mathrm{p}=0.21)$ Table 5 . Comparison of discontinuation rate between users of DMPA $(68 \%)$ and for Noristerat $(60 \%)$ did not reveal any statistically significant difference $(\mathrm{p}=0.67)$. Prolonged spotting was the second reason given by both groups accounting for $16 \%$ and $20 \%$ respectively. This was closely followed by irregular/intermenstrual bleeding observed in $11 \%$ of DMPA and $15 \%$ of Noristerat users respectively (Table 6).

\section{DISCUSSION}

Progesterone only injectable contraceptive is a widely used method of contraception among the women attending our family planning clinic, and it is the second commonly accepted method only next to intrauterine contraceptive device. The prevalence of $21.55 \%$ is comparable to $22.1 \%$ reported from Osogbo, $21.9 \%$ in Ilorin, and $23.3 \%$ in Port harcourt but higher than the $7.9 \%$ and $14.2 \%$ reported from Ibadan and Jos respectively. ${ }^{7-11}$ However, this study prevalence was lower than $26 \%, 50 \%$ and $71.8 \%$ reported from Isagamu, Zaria and Abia in respectively in different geopolitical zones in Nigeria. ${ }^{12-14}$ In general, there seems to be regional variation in the use progesterone only contraceptives which may be as a result of cultural and religious beliefs and individual client perception of the contraceptive method. ${ }^{9}$

All the women in this study were married. This is similar to findings Oye-Adeniran et al, where their subjects were sexually active, fecund and married. ${ }^{15}$ The largest proportion of the women in this study $(83.5 \%)$ had secondary and tertiary education, only $5.5 \%$ had no form of education. This high percentage was expected as studies have shown that formal education significantly increases the utilization of contraceptive methods. ${ }^{2}$

This study also showed that for women in both groups (DMPA and Noristerat), there was an observed increased in the mean weight over 12 months which was statistically significant. The DMPA group gained $3.1 \mathrm{~kg}$ (4.5\%) compared to $2.4 \mathrm{~kg}(3.7 \%)$ in the Noristerat group. This is similar to the findings by Moore et al, Mia et al and Berenson et al. ${ }^{16-18}$ Hormonal contraceptives (injectables) have been found to increase intake of food by stimulating the appetite and decreasing energy expenditure. DMPA and Noristerat despite normal diet, has also been found to cause slight water retention hence contributing to increase in weight gain. ${ }^{19}$ However, age, caloric intake, race, exercise among other factors can contribute to the different changes in weight observed amongst the subjects. Lifestyle changes are often contributory or causative. ${ }^{19}$ However, the number of patients considering weight gain to be a major problem was low (5\% for Depo-Provera and 5\% for Noristerat). This may be explained by the fact that many Nigerian women usually perceive weight gain as a sign of good health and vitality leading to high socio-economic status of the woman. ${ }^{19}$ However, this might be hazardous to patients who are overweight ab-initio as any weight gain might tilt them towards obesity and its accompanying morbidities. Therefore, overweight subjects are preferably excluded from the use of hormonal contraceptives.

The incidence of menstrual abnormalities increased steadily from the second and third months of use to the end of 12 months in both groups of women. Amenorrhea accounted for most of the menstrual abnormalities in both groups, with an incidence of $60 \%$ in the Depo-Provera group, and $57 \%$ in the Noristerat group. This is similar to the findings of Kaunnitz, and Polanecsky et al, whose studies showed that at least $50 \%$ of DMPA users will be amenorrhoeic by 12 months of use, but contrasted with the study of Chowdhury23 who reported a mere $12.7 \%$ incidence of amenorrhea in patients who used Noristerat for 12 months. ${ }^{20-22}$

The discontinuation rates at 6 months and 1 year were $13 \%$ and $28 \%$ respectively in the DMPA group. This translates to continuation rates of $87 \%$ and $72 \%$ which are quite high when compared to a similar study by Polaneczky et al, where continuation rates were $65 \%$ and $42 \%$ at 6 months and 1 year respectively. ${ }^{22}$ In the Noristerat group, continuation rates were $93.00 \%$ at 2 months and $80 \%$ at 1 year. This is similar to findings of Chowdhury et al with continuation rate of $75 \%$ at 12 months. ${ }^{23}$ Among reasons for discontinuation not related to desire for pregnancy, amenorrhea tops the list followed by prolonged spotting and irregular/intermenstrual bleeding. The reason for this may not be unconnected to importance women attached to the menstrual bleeding, lack of which could be referred to culturally as early symptoms of impending infertility. Many of the patients when asked about the menstrual irregularities experienced, complained about their perception of having reached menopause and this was not acceptable to them. ${ }^{14}$ There was no report of accidental pregnancy during follow-up among the subjects. This supports previous reports of the effectiveness of the contraceptive method and its association with low failure rate..$^{8,19}$

This study has limitations in its retrospective design. However, the significant weight gain in users of injectable contraceptives was tolerable as very few of the users perceive this as a problem. Amenorrhea, prolonged spotting and irregular/intermenstrual bleeding are common side effects, experienced by the users. Optimal counseling at onset of usage and re-enforcement during follow-up is essential to encourage use and perhaps reduce discontinuation rates among users of injectable contraceptives in long term.

\section{CONCLUSION}

There were significant weight gains between users of DMPA and Noristerat which was not considered a 
problem. Amenorrhoea was the commonest menstrual abnormality responsible for discontinuation of either method.

\section{Funding: No funding sources}

Conflict of interest: None declared

Ethical approval: The study was approved by the Institutional Ethics Committee

\section{REFERENCES}

1. Sedgh G, Bankole A, Oye-Adeniran B, Adewole IF, Singh S, Hussain R. Unwanted pregnancy and associated factors among Nigerian women. International family planning perspectives. 2006:175-84.

2. Takkar N, Goel P, Saha PK, Dua D. Contraceptive practices and awareness of emergency contraception in educated working women. Ind $\mathrm{J}$ Med Sci. 2005;59(4):143-9.

3. Igwegbe AO, Ugboaja JO. Clinical experience with injectable progestogen only contraceptives at Nnamdi Azikiwe University Teaching Hospital. Nnewi, Nigeria. J Medicine Med Sci. 2010;1(8):3459.

4. Sule S, Shittu O. Weight changes in clients on hormonal contraceptives in Zaria, Nigeria. Afri J Rep Health. 2005;9(2):92-100.

5. Adeyemi AS, Adekanle DA. Progesterone only injectable contraceptive, Experience of women in Osogbo, South Western Nigeria. Dept of O and G Ladoke Akintola University of Tech. Annals Afr. Med. 2012;11(1):27-31.

6. Hatcher RA, Trussell J, Nelson AL. Contraceptive technology. $20^{\text {th }}$ ed. New York: Ardent Media; 2011.

7. Adeyemi DA, Adekanle. Progesterone only injectable contraceptive, Experience of women in Osogbo, South Western Nigeria. Dept of O and G Ladoke Akintola University of Tech. Annals of Afr. Med. 2012;11(1):27-31.

8. Balogun OR, Raji HO. Clinical experience with injectable progestogen-only contraception at university of ilorin teaching hospital: a five-year review. Nigerian Postgraduate Med J. 2009;16:2603.

9. Njoku CO, Emechebe CI, Iklaki CU, Njoku AN, Ukaga JT. Progestogen-Only Injectable Contraceptives: The Profile of the Acceptors, Side Effects and Discontinuation in a Low Resource Setting, Nigeria. Open J Obstet Gynecol. 2016;6:189-95.

10. Konje JC, Oladini F, Otolorin EO, Ladipo OA. Factors determining the choice of contraceptive method at the family planning clinic, University
College Hospital, Ibadan. Nig $\mathrm{Br} \mathrm{J}$ Fam Plan. 1998;24:107-10.

11. Mutihir JT, Pam VC. Overview of contraceptives use in Jos University Teaching Hospital, North Central Nigeria. Niger J Clin Pract. 2008;11:139-43.

12. Akadri AA, Odelola OI. Progestogen-only injectable contraceptive: Acceptor prevalence and client experience at Sagamu, Nigeria. Niger Postgrad Med J. 2017;24:178-81.

13. Ameh N, Sule ST. Contraceptive choices among women in Zaria, Nigeria. Niger $\mathbf{J}$ Clin Pract. 2007;10:205-7.

14. Chigbu B, Onwere S, Aloka C, Kamanu C, Okoro O. Contraceptive choices of women in rural south eastern Nigeria. Niger J Clin Pract. 2010;13:195-9.

15. Oye Adeniran BA, Adewole IF, Odeyemi KA, Ekenam EE. Contraceptive prevalence among young women in Nigeria. J Obst Gynae. 2005;25(2):182-5.

16. Moore K, Valdek K, Mc Dougall C, Fink N. Weight Gain and hormonal contraceptives. Contracept. 1995;52(4):215-9.

17. Mia AR, Siddiqui N, Khan MR, Shampa SS, Rukunuzzaman AN. Effect of prolonged use of injectable hormonal contraceptives on blood pressure and body weight. Mymensingh Med J. 2004;13(1):30-2.

18. Berenson AB, Rahman M. Changes in weight, total fat, percent body fat, and central-toperipheral fat ratio associated with injectable and oral contraceptive use. Am J Obstet Gynecol. 2009;200(3):329.e1-329.e8.

19. Ojule JD, Orji VK, Okongwu C. A Five-year review of the complications of progestogen only injectable contraceptive at the University of port-harcourt teaching hospital. Nigerian Journal of Medicine. 2010;19:87-95.

20. Kaunnitz AM. Long acting hormonal contraception, assessing impact on bone density, weight and mood. Int J Fert W Omen Med. 1999;44(2):110-7.

21. Kaunnitz AM. Long acting injectable contraception: Depot medroxylprogesterone acetate. Am J Obst Gynae. 1994;170:1543-9.

22. Polanecky M, Gaernacei M, Alon J. Early experience with contraceptive use of DMPA in an inner city population. Family Planning Perspectives. 1996;1748.

23. Chowdhury TA. A clinical study on injectable contraceptive-Noristerat. Bangladesh Med J. 1985;14(2-3):28-35.

Cite this article as: Oshodi YA, Agbara JO, Adefashola OO, Akinlusi FM, Olalere HF, Kuye TO. Weight gain and menstrual abnormalities between users of depo-provera and noristerat. Int J Reprod Contracept Obstet Gynecol 2019;8:2226-31. 